\title{
Fabrication of Silica Microspheres (HB/A@SI-MNS) for Hafnium and Zirconium Recovery from Zirconyl Leach Liquor
}

\author{
Mahmoud O. Abd El-Magied ${ }^{1, *(\mathbb{D})}$, Waheed M. Salem ${ }^{2}$, Ahmad A. Daher ${ }^{1}$ and \\ Emad A. Elshehy ${ }^{1}$ \\ 1 Nuclear Materials Authority, P.O. Box 530, El Maadi, Cairo 11936, Egypt; doctor_daher@yahoo.com (A.A.D.); \\ eelshehy@yahoo.com (E.A.E.) \\ 2 Chemistry Department, Faculty of Science, Damanhur University, Damanhur 22511, Egypt; \\ Waheedsalem1979@yahoo.com \\ * Correspondence: mahmoud_nma@yahoo.com; Tel.: +20-100-984-9016
}

Received: 17 February 2018; Accepted: 21 March 2018; Published: 24 March 2018

\begin{abstract}
This work describes the synthesis of silica microspheres using sodium silicate obtained as a byproduct in the production of Egyptian Rosetta zircon concentrate. The obtained mesoporous silica microspheres were further modified with aminopropyltriethoxy silane and 2,4-Dihydroxybenzaldehyde to produce Schiff's base silica sorbent (HB/A@Si-MNS). HB/A@Si-MNS was used for the selective extraction of hafnium from zircon mineral leach liqueur. The fabrication process and surface properties of HB/A@Si-MNS were confirmed by the means of X-ray Fluorescence (XRF), scanning electron microscop (SEM), energy depressive X-ray (EDX), Fourier-transform infrared spectroscopy (FT-IR), and elemental analysis. The uptake behavior of HB/ A@Si-MNS towards Zr(IV) and Hf(IV) ions were studied under different experimental conditions. Adsorption curves indicate that the uptake of $\mathrm{Zr}(\mathrm{IV})$ and $\mathrm{Hf}(\mathrm{IV})$ on $\mathrm{HB} / \mathrm{A} @ S i-M N S$ is a spontaneous, endothermic monolayer system controlled by intraparticle diffusion. Elution efficiencies were found to be $94 \%$ and $98 \%$ for $\mathrm{Zr}(\mathrm{IV})$ and Hf(IV), respectively. The regenerated HB/A@SI-MNS showed uptake capacity comparable to that of fresh ones over 3 cycles. The results of the extraction of $\mathrm{Hf}(\mathrm{IV})$ than $\mathrm{Zr}(\mathrm{IV})$ from Rosetta zircon concentrate show that HB/ A@SI-MNS has a preferential selectivity towards $\mathrm{Hf}(\mathrm{IV})$ than $\mathrm{Zr}(\mathrm{IV})$. Therefore, the studied material may be promising for the selective separation of $\mathrm{Hf}(\mathrm{IV})$ from $\mathrm{Zr}(\mathrm{IV})$.
\end{abstract}

Keywords: silica; kinetics; zirconium; hafnium; extraction

\section{Introduction}

Zirconium and hafnium coexist in nature as the mineral zircon, and less commonly as baddeleyite. The zircon mineral $\left(\mathrm{Zr}(\mathrm{Hf}) \mathrm{SiO}_{4}\right)$ is one of the most stable chemical compounds due to the strong bond between zirconia and silica [1,2]. This is the result of the high coordination of bisdisphenoid $\mathrm{ZrO}_{8}$ in a tetragonal structure with the tetrahedral $\mathrm{SiO}_{4}[3,4]$. Several industrial methods are used to decompose zircon, including its fusion with caustic soda at $650{ }^{\circ} \mathrm{C}$ or with soda ash at $900{ }^{\circ} \mathrm{C}$. Together, zirconium and hafnium have potential in numerous industries, including catalyst, pigments, and alloys. One amongst the foremost necessary uses of zirconium and hafnium is within the nuclear industry as cladding for the nuclear material in reactors [5-7]. High corrosion resistance and the low neutron cross section absorption of nuclear grade zirconium make this metal ideally suited to be used in highly robust environments. Hafnium, on the other hand, is also used in the nuclear industry, but due to its high neutron absorption coefficient, it is used as control rods in the nuclear process to control and regulate the nuclear reactions [7]. Ultra-pure $\mathrm{Zr}$ metal ( $\mathrm{Hf}<100 \mathrm{ppm}$ ) is needed to 
improve the efficiency of a nuclear reactor in the nuclear industry. The difficulty in separation and the natural abundance techniques makes hafnium a scarce commodity and very expensive [8,9]. There are considerable efforts to develop new and cheaper methods to extract zirconium and hafnium ions. Adsorption on organic resins or inorganic oxides is one of the most efficient methods. Inorganic adsorbents are characterized by good selectivity, low price, rapid kinetics, mechanical stability, and no swelling [10-14].

Recently, some articles have reported on the preparation and application of silica from various sources [15-20]. Many chelating moieties, such as amine, sulfonate, crown ether and phosphonic were immobilized on silica surfaces through a physical or chemical interaction between silica's network and functional groups. Sodium silicate is known as the main source for the preparation of commercially available silica. Sodium silicate was obtained as a waste product through the extraction of $\mathrm{Zr}$ (IV) and Hf(IV) from Egyptian Rosetta zircon concentrate. The present study seeks to determine the feasibility of zircon mineral processing in terms of the preparation of zirconium/hafnium oxychlorides, mesoporous silica fabrication and modification to separate $\mathrm{Hf}(\mathrm{IV})$ and $\mathrm{Zr}(\mathrm{IV})$ ions from a zircon mineral concentrate. To achieve this goal, the waste obtained from the Egyptian Rosetta zircon concentrate was treated to obtain pure sodium silicate. The silica obtained was characterized and was further modified with Schiff base functionality. The obtained silica (HB/A@Si-MNS) was used for the selective extraction of $\mathrm{Hf}(\mathrm{IV})$ from $\mathrm{Zr}(\mathrm{IV})$ ions at different experimental conditions of $\mathrm{pH}$, time, concentration, and temperature.

\section{Materials and Methods}

\subsection{Materials}

Sodium silicate was obtained from the Egyptian Rosetta zircon mineral (purity 97\%) via alkali fusion with sodium hydroxide $(95.9 \%)$. Hexadecyltrimethylammonium bromide (CTAB), 2,4-Dihydroxybenzaldehyde (HB), 3-Aminopropyltriethoxysilane (APTS), zirconium oxychloride $\left(\mathrm{ZrOCl}_{2} \cdot 8 \mathrm{H}_{2} \mathrm{O}\right)$ and hafnium tetrachloride $\left(\mathrm{HfCl}_{4}\right)$ are Aldrich (St. Louis, MO, USA) and Fluka (Munich, Germany) products. All other chemicals are ADWICK (Cairo, Egypt) products.

\subsection{Zircon Mineral Concentrates Processing}

A type 316-L stainless steel crucible with dimensions of $15 \mathrm{~cm}$ in height and $10 \mathrm{~cm}$ in diameter was used as the reaction vessel. A sample of $250 \mathrm{~g}$ of Rosetta zircon concentrate (purity $97 \%$ as shown in Table 1) was mixed with $312.5 \mathrm{~g}$ of sodium hydroxide and charged to the reaction vessel. The reaction vessel was fed to the electric furnace and the reaction temperature was adjusted at $650{ }^{\circ} \mathrm{C}$ for $2 \mathrm{~h}$. The fusion product resulted (sodium zirconate and silicate) was washed with hot distilled water (4 times of the product weight). The residual hydrous zirconium was dried before leaching in hot $\mathrm{HCl}$ $(2: 1 w / w)$ to produce $\mathrm{Zr}(\mathrm{Hf}) \mathrm{OCl}_{2} \cdot 8 \mathrm{H}_{2} \mathrm{O}$. The latter was then allowed to crystallize in ice. The formed crystals were separated from the mother liquor by decantation and the pure crystals were redissolved in dilute $\mathrm{HCl}[4]$.

Table 1. Major and trace constituents of Rosetta zircon concentrate.

\begin{tabular}{cccc}
\hline \multicolumn{2}{c}{ Major Constituents } & \multicolumn{2}{c}{ Trace Constituents } \\
\hline Constituent & Concentration, $\%$ & Constituent & Concentration, \% \\
\hline $\mathrm{ZrO}_{2}$ & 64.42 & $\mathrm{U}_{3} \mathrm{O}_{8}$ & 0.04 \\
$\mathrm{HfO}_{2}$ & 1.46 & $\mathrm{ThO}_{2}$ & 0.02 \\
$\mathrm{SiO}_{2}$ & 32.23 & $\mathrm{REO}$ & 0.07 \\
$\mathrm{Fe}_{2} \mathrm{O}_{3}$ & 0.14 & $\mathrm{MgO}$ & 0.02 \\
$\mathrm{TiO}_{2}$ & 0.22 & $\mathrm{CaO}$ & 0.01 \\
$\mathrm{P}_{2} \mathrm{O}_{5}$ & 0.13 & $\mathrm{Al}_{2} \mathrm{O}_{3}$ & 0.06 \\
- & - & $\mathrm{K}_{2} \mathrm{O}$ & $<0.01$ \\
- & - & $\mathrm{Na}_{2} \mathrm{O}$ & $<0.01$ \\
\hline
\end{tabular}




\subsection{Recycling of Silicate Waste for Fabrication of Mesoporous Silica Microspheres}

A sample of mesoporous silica was prepared in a one pot synthesis assembly process using the sodium silicate obtained from the above step in the presence of $\mathrm{CTAB}$ as a cationic structure-directing agent. The silicate solution $\left(25 \% \mathrm{SiO}_{2}, 17 \% \mathrm{NaOH}\right)$ was diluted using diluted $\mathrm{CH}_{3} \mathrm{COOH}$ to adjust the solution $\mathrm{pH}$ at 8 . The surfactant and an amount of acetic acid equivalent to the hydroxide content of the sodium silicate solution were mixed at $25^{\circ} \mathrm{C}$ and added to the sodium silicate solution. The mixture was stirred vigorously for $2 \mathrm{~h}$ at $55^{\circ} \mathrm{C}$. The formed silica microspheres $\left(\mathrm{pH} 8 ; \mathrm{CTAB} / \mathrm{SiO}_{2}\right.$ molar ratio of 0.45 ) were stirred for about $24 \mathrm{~h}$. This allowed the formation of the channels framework under basic $\mathrm{pH}$ conditions, where both the silica precursor and the surfactant were primarily charged species. Silica was filtered off, washed with water and ethanol to remove the surfactant, and the as-synthesized products were calcined [20].

\subsection{Synthesis of HB/A@Si-MNS Meso-sorbent}

Two $\mathrm{mL}$ of 3-Aminopropyltriethoxysilane (APTS) were dissolved in $100 \mathrm{~mL}$ of distilled water acidified with acetic acid ( $\mathrm{pH}$ 4). Two grams of activated silica (dried at $150{ }^{\circ} \mathrm{C}$ for $18 \mathrm{~h}$ ) were added to the above solution (the hydrolyzed APTS) and stirred for $2 \mathrm{~h}$ at room temperature. The formed monoamine modified silica (MAMS) was washed repeatedly with water, ethanol, and acetone several times. The washed material was then dried in an oven at $120^{\circ} \mathrm{C}$ for another $2 \mathrm{~h}$. One gram of MAMS was added to $0.5 \mathrm{~g}$ of 2,4-dihydroxybenzaldehyde (HB) and dissolved in $20 \mathrm{~mL}$ methanol. The mixture was refluxed for $72 \mathrm{~h}$ at $75-80{ }^{\circ} \mathrm{C}$. The product, referred to as HB/A@Si-MNS, was then filtered off, washed, and dried.

\subsection{Characterization of Fabricated Materials}

A major and trace elemental analysis of the zircon sample was performed using elemental analysis and X-ray fluorescence (Philips PW X-Unique II X-ray spectrometer, Philips Co., Amsterdam, The Netherlands). The Brunauer-Emmett-Teller (BET) surface area, pore volume, and average pore diameter of the materials were measured by a Quanta chrome NOVA automated gas sorption system using nitrogen as the adsorbate. A Fourier-transform infrared spectroscopy (FT-IR) (Nexeus-Nicolite-640-MSA FTIR, Waltham, MA, USA) and Environmental Scanning Electron Microscope (ESEM, EXL 130, Philips Co., Amsterdam, The Netherlands) were used to characterize the fabricated materials.

\subsection{Adsorption Experiments}

Stock solutions (1000 $\mathrm{mg} \mathrm{L}^{-1}$ ) of $\mathrm{Zr}(\mathrm{IV})$ and $\mathrm{Hf}(\mathrm{IV})$ were prepared by dissolving 3.533 and $1.8 \mathrm{~g}$ of zirconium oxychloride octahydrate $\left(\mathrm{ZrOCl}_{2} \cdot 8 \mathrm{H}_{2} \mathrm{O}\right)$ and hafnium tetrachloride $\left(\mathrm{HfCl}_{4}\right)$, respectively, in a liter of $2 \mathrm{M} \mathrm{HCl}$. The concentration of $\mathrm{Zr}(\mathrm{IV})$ and $\mathrm{Hf}(\mathrm{IV})$ ions in both synthetic and real sample mixtures were measured by Inductively Coupled Plasma Mass Spectrometry (Scan-16-ICP-MS, Thermo Finnigan, San Jose, CA, USA). Uptake experiments at different time intervals were done by placing $0.1 \mathrm{~g}$ of HB/A@Si-MNS in a round flask containing $100 \mathrm{~mL}$ of the metal ion solution $\left(100 \mathrm{mg} \mathrm{L}^{-1}\right)$ for the required interval time. The contents of the flask were shaken on a Vibromatic-384 shaker (Selecta, Barcelona, Spain) at $300 \mathrm{rpm}$ and at room temperature. The residual concentrations of $\mathrm{Zr}$ (IV) or Hf(IV) ions were determined spectrophotometrically [21] and were used to calculate the uptake using Equation (1) [22].

$$
q=\left(C_{i}-C_{f}\right) \times \frac{V}{W}
$$

where $q$ is the uptake $\left(\mathrm{mg} \mathrm{g}^{-1}\right), C_{i}$ and $C_{f}$ are the initial and final concentrations of the metal ion in adsorption media $\left(\mathrm{mg} \mathrm{L}^{-1}\right), V$ is the volume $(\mathrm{L})$ and $W$ is the HB/A@Si-MNS weight (g). Uptake experiments under controlled $\mathrm{pH}$ were carried out following the above procedures while keeping the equilibrating time at $30 \mathrm{~min}$ for the two metal ions. Diluted solutions of $\mathrm{HCl}$ and $\mathrm{NaOH}$ were used to 
adjust the $\mathrm{pH}$ of the medium. The effect of the initial metal ion concentrations on the adsorption was carried out at different temperatures $\left(25,30,35\right.$ and $\left.40^{\circ} \mathrm{C}\right)$.

\section{Results and Discussions}

\subsection{Characterization of HB/A@Si-MNS}

The successful fabrication of silica particles, Figure 1, from Rosetta zircon concentrates (purity $97 \%$ as shown in Table 1) was confirmed by different methods. The silanol ( $\mathrm{Si}-\mathrm{OH})$ groups on the silica surface play an important role in the surface modification by forming covalent bonds with APTS in a very slow condensation reaction. The synthesis routes of mono-amine modified silica (MAMS) and the formation of Schiff base modified silica (HB/A@Si-MNS) are shown in Figure 1. The FT-IR spectrum of the pristine material, Figure 2, displays a number of characteristic bands; at 3448 (stretching vibration of the H-bonded silanol group $v(-\mathrm{Si}-\mathrm{OH})$ along with physisorbed water $v(-\mathrm{OH})) ; 1085 v(-\mathrm{Si}-\mathrm{O}-\mathrm{Si}-)$ of siloxane backbone); $954 v(-\mathrm{Si}-\mathrm{OH})$ of the free silanol group; $799 \mathrm{~cm}^{-1} v\left(\mathrm{SiO}_{4}\right)$ (tetrahedron ring) and at $466 \mathrm{~cm}^{-1} v(-\mathrm{Si}-\mathrm{O}-\mathrm{Si}-)$ deformation.

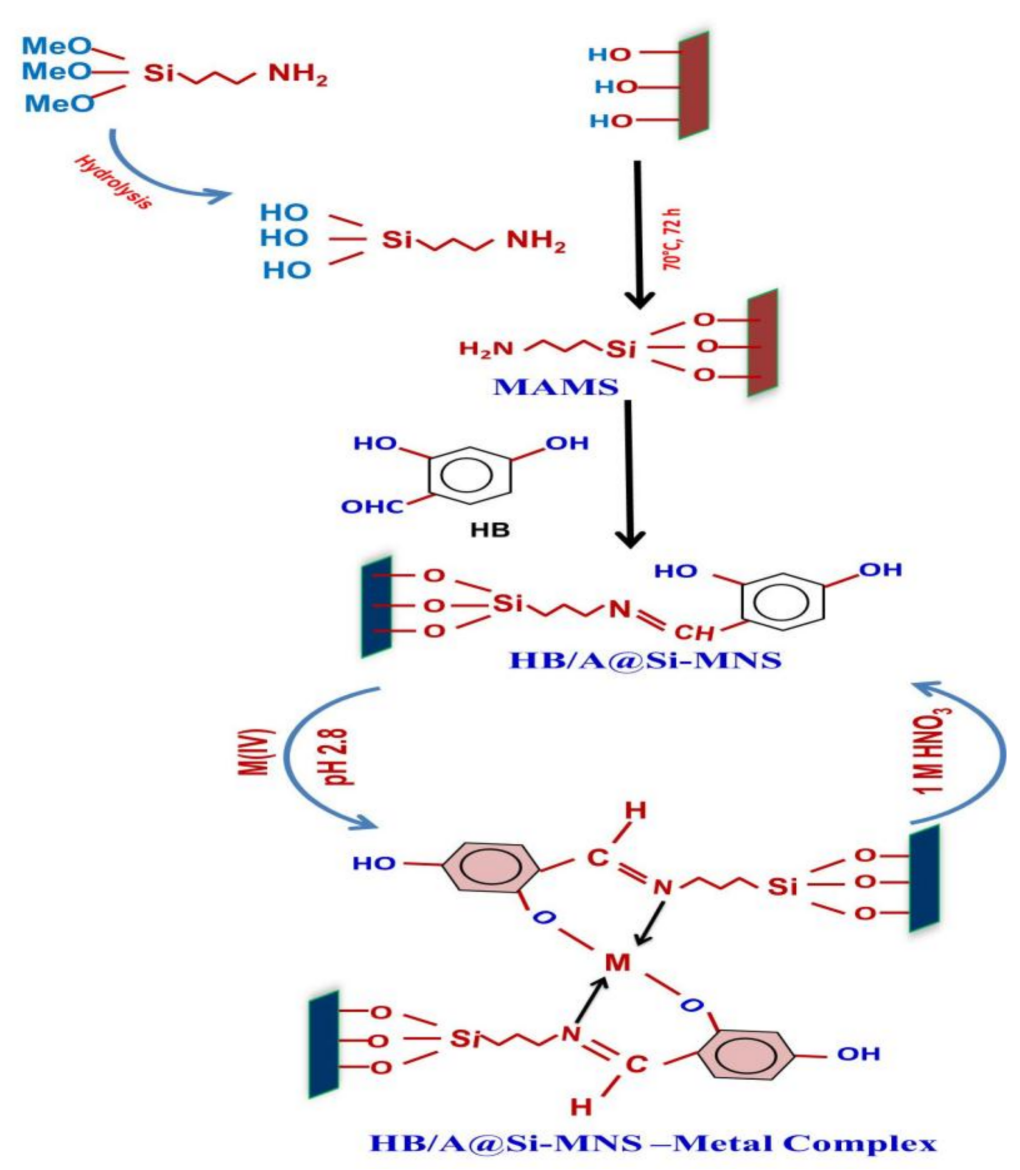

Figure 1. Fabrication of the HB/A@Si-MNS through the post-grafting approach.

The spectra of the modified silica display similar characteristic bands along with new bands. The spectrum of the modified silica (MAMS and HB/A@Si-MNS) is characterized by the appearance of two weak bands at $2361 \mathrm{~cm}^{-1}$ and $2964 \mathrm{~cm}^{-1}$ that were assigned to $v\left(\mathrm{CH}_{2}\right)$ stretching. In addition, there is another new band at $1440 \mathrm{~cm}^{-1}$, which was assigned to $v(\mathrm{C}-\mathrm{N})$. The spectrum showed that the amino group was covalently grafted to the silica successfully, as shown in Figure 1. 


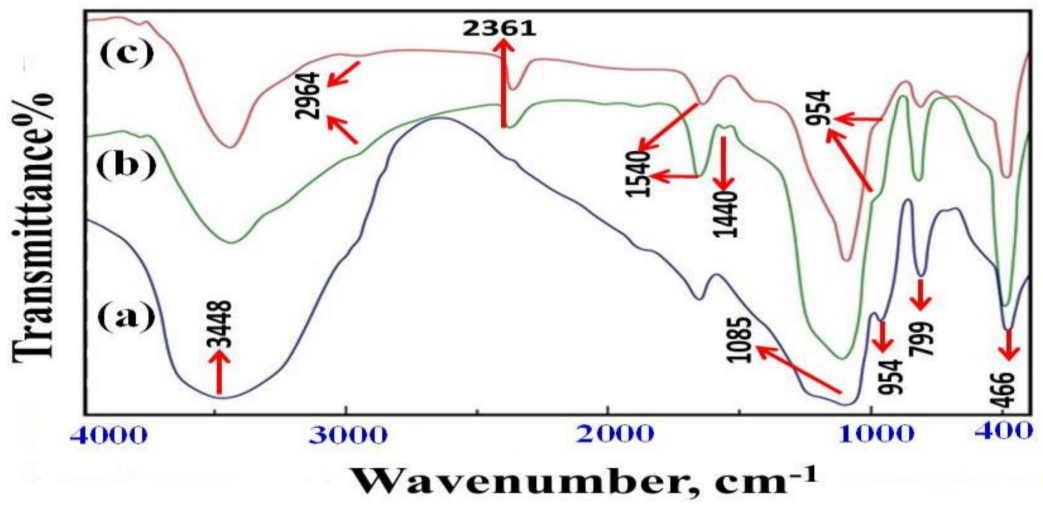

Figure 2. Fourier-transform infrared spectroscopy (FT-IR) spectra of silica from silicate waste (a), mono-amine modified silica (MAMS) (b) and HB/A@Si-MNS (c).

The BET surface area, pore volume, and average pore diameter for the unmodified and modified silica were determined and given in Figure 3A. Samples showed nitrogen adsorption-desorption isotherms typically of type IV with H1 hysteresis loop. Samples exhibited a pronounced steep condensation step for relative pressures $0.76-0.95$ arising from the condensation of the nitrogen inside the mesopores, indicating the good structural order of the fabricated materials. Moreover, the high surface area $\left(266 \mathrm{~cm}^{2} \mathrm{~g}^{-1}\right)$ and large pore size $\left(0.85 \mathrm{~cm}^{3} \mathrm{~g}^{-1}\right)$ with high pore opening $(4.685 \mathrm{~nm})$ of this material are excellent advantages of the fabricated of meso- adsorbent for capture $\mathrm{Zr}$ (IV) from $\mathrm{Hf}(\mathrm{IV})$ ions. A decrease in the surface area $\left(111.5 \mathrm{~cm}^{2} \mathrm{~g}^{-1}\right)$, pore volume $\left(0.44 \mathrm{~cm}^{3} \mathrm{~g}^{-1}\right)$, and pore diameter $(3.20 \mathrm{~nm})$ after the functionalization of fabricated cylindrical mesoporous silica with HB provides further evidence that the organic moieties were embedded inside the mesopore of the modified silica. This may be attributed to the partial blocking obtained by the modifying silica that hinders the adsorption of nitrogen molecules [23-25].
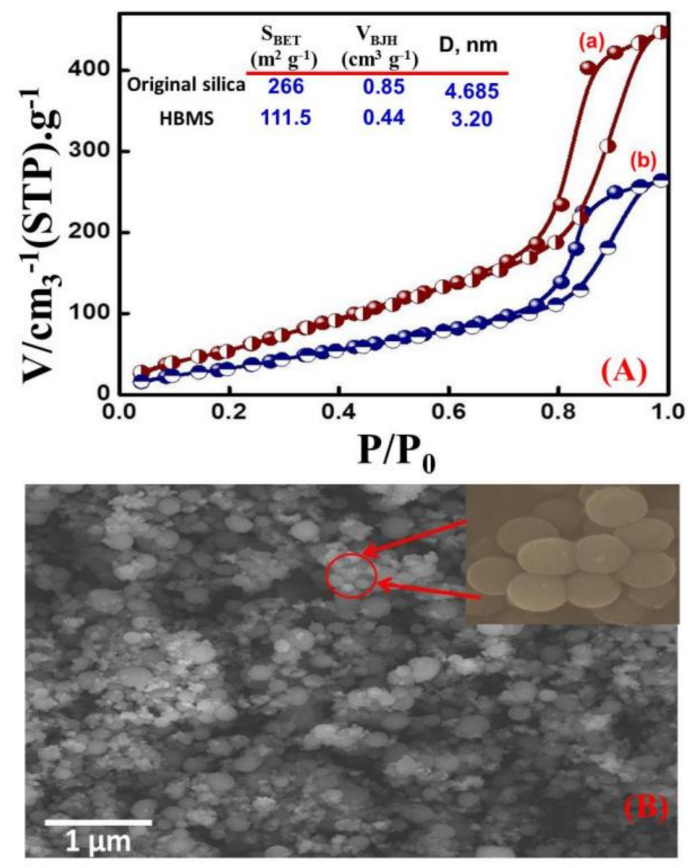

Figure 3. (A) $\mathrm{N}_{2}$ isotherms of the free silica (a) and HB/A@Si-MNS (b); insert are $\mathrm{N}_{2}$ isotherms parameter and (B) scanning electron microscope (SEM) image of HB/A@Si-MNS. 
The scanning electron microscope (SEM) showed uniform particles with a well-defined spherical morphology with particle sizes ranging from 250 to $300 \mathrm{~nm}$ (Figure 3B). Therefore, the combined characteristics of both the SEM and $\mathrm{N}_{2}$ adsorption reveals the appearance of HB/A@Si-MNS as a uniform and cylindrical mesopores material. On the other hand, the energy depressive X-ray (EDX) of both non functionalized silica and HB/A@Si-MNS is characterized by nitrogen and carbon lines. Elemental analyses of HB/ A@Si-MNS give 28.3\% (C), 3.21\% $(\mathrm{H})$ and $2.98 \%(\mathrm{~N})$. The content of $(=\mathrm{N}-)$ group was found to be $2.14 \mathrm{mmol} \mathrm{g}^{-1}$ which also confirms the success of the modification process.

\subsection{Adsorption Assays of $\mathrm{Zr}(I V)$ and $H f(I V)$ Ions}

\subsubsection{Effect of $\mathrm{pH}$ on the Batch Adsorption Process}

The adsorption of $\mathrm{Zr}(\mathrm{IV})$ and $\mathrm{Hf}(\mathrm{IV})$ by HB/A@Si-MNS as a function of $\mathrm{pH}$ was carried out over the $\mathrm{pH}$ range of 1-3 and $20 \mathrm{~min}$ and is shown Figure 4. The highest uptake value of 19 and $46 \mathrm{mg} \mathrm{g}^{-1}$ was observed at $\mathrm{pH} 2.8$ for $\mathrm{Zr}(\mathrm{IV})$ and $\mathrm{Hf}(\mathrm{IV})$, respectively. The aqueous chemistry of zirconium and hafnium is extensively influenced by hydrolysis and polymerization reactions. The hydrolysis of the process depends on the solution $\mathrm{pH}$ and can exist even in very acidic solutions $\left(\mathrm{Hf}(\mathrm{OH})^{3+}\right.$ is known to exist even at $\mathrm{pH}$ below 1). Generally, the hydrolysis and polymerization reaction of zirconium or hafnium is represented by Equation (2). Chloride ions exhibit weak complexing action on zirconium and hafnium (Equation (3)) [26-29].

$$
\begin{gathered}
n M^{4+}+m \mathrm{H}_{2} \mathrm{O} \leftrightarrow M_{n}(\mathrm{OH})_{m}^{4 n-m}+m \mathrm{H}^{+} \\
M^{4+}+n \mathrm{Cl}^{-} \leftrightarrow \mathrm{MCl}_{n}^{4-n}
\end{gathered}
$$

where $M$ represents $\mathrm{Zr}$ or Hf. In the present work, the dominating zirconium and hafnium species in the aqueous solutions are cationic species. Above $3 \mathrm{M} \mathrm{HCl}$ solution, the predominant species change to be neutral, where anionic complexes are not detected when the concentration of $\mathrm{HCl}$ is less than 7 M [26-29]. At lower pH values, the active groups of the HB/A@Si-MNS get protonated and the interaction between the protonated HB/A@Si-MNS and cationic species of $\mathrm{Zr}(\mathrm{IV})$ and $\mathrm{Hf}(\mathrm{IV})$ is reduced. The interaction of $\mathrm{Zr}(\mathrm{IV})$ and $\mathrm{Hf}(\mathrm{IV})$ with the HB/A@Si-MNS may take place through a complex formation with the donor sites of amino groups, as well as the oxygen atoms of the phenolic hydroxyl group, and coordination type, as suggested in Figure $1[1,2,9,21,24]$. The observed decrease in the uptake of $\mathrm{Zr}(\mathrm{IV})$ and $\mathrm{Hf}(\mathrm{IV})$ at $\mathrm{pH}>3$ can be explained on the basis of the formation of various oligomeric and monomeric hydrolyzed species of $\mathrm{Zr}(\mathrm{IV})$ and $\mathrm{Hf}(\mathrm{IV})$ with lower adsorption affinities to HB/A@Si-MNS.

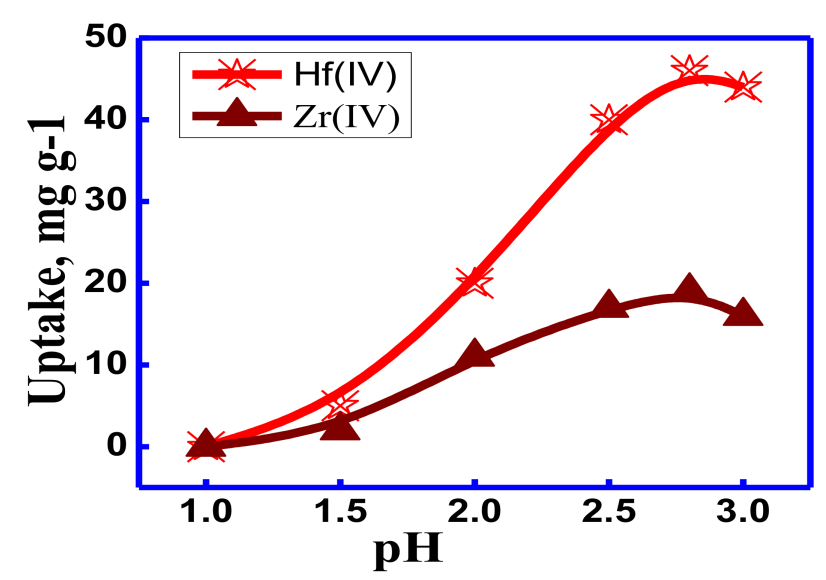

Figure 4. pH-dependant curve of the adsorption of $\mathrm{Zr}(\mathrm{IV})$ and $\mathrm{Hf}(\mathrm{IV})$ on HB/A@Si-MNS at a concentration of $100 \mathrm{mg} \mathrm{L}^{-1}$ and $25^{\circ} \mathrm{C}$. 


\subsubsection{Adsorption Kinetics}

Studying the effect of contact time on the uptake process of $\mathrm{Zr}(\mathrm{IV})$ and $\mathrm{Hf}(\mathrm{IV})$ is essential to determine the optimum operating conditions for the full-scale batch reactor. The uptake of $\mathrm{Zr}(\mathrm{IV})$ and $\mathrm{Hf}(\mathrm{IV})$ on HB/A@Si-MNS, at $25^{\circ} \mathrm{C}$ and $\mathrm{pH}$ value of 2.8, were shown in Figure 5a. The equilibrium was attained within $20 \mathrm{~min}$ for both metal ions. The adsorption data were treated according to pseudo-first (Equation (4)) and pseudo-second-order (Equation (5)) kinetic models [30,31].

$$
\begin{gathered}
\log \left(q_{e}-q_{t}\right)=\log q_{1}-\frac{k_{1}}{2.303} t \\
\frac{t}{q_{t}}=\frac{1}{k_{2} q_{2}^{2}}+\frac{t}{q_{e}}
\end{gathered}
$$

where $q_{e}$ and $q_{t}$ refer to the adsorbed amount of $\mathrm{Zr}(\mathrm{IV})$ or $\mathrm{Hf}(\mathrm{IV})\left(\mathrm{mg} \mathrm{g}^{-1}\right)$ at equilibrium and at time $t$ (min), respectively. $k_{1}$ and $k_{2}$ are the overall rate constants of pseudo-first and pseudo-second order, respectively. Intercepts and slopes of the straight-line plots of Figure 5b,c were used to calculate the maximum theoretical capacity $\left(q_{1}\right.$ and $\left.q_{2}\right), k_{2}$ and $k_{1}$ as given in Table 2. Obviously, a satisfactory agreement was obtained between calculated $q_{2}$ of the pseudo-second model rather than that of the pseudo-first-order $\left(q_{1}\right)$. This implies that the adsorption process proceeds according to the pseudo-second-order kinetics and depends upon the metal ion and active site concentrations.
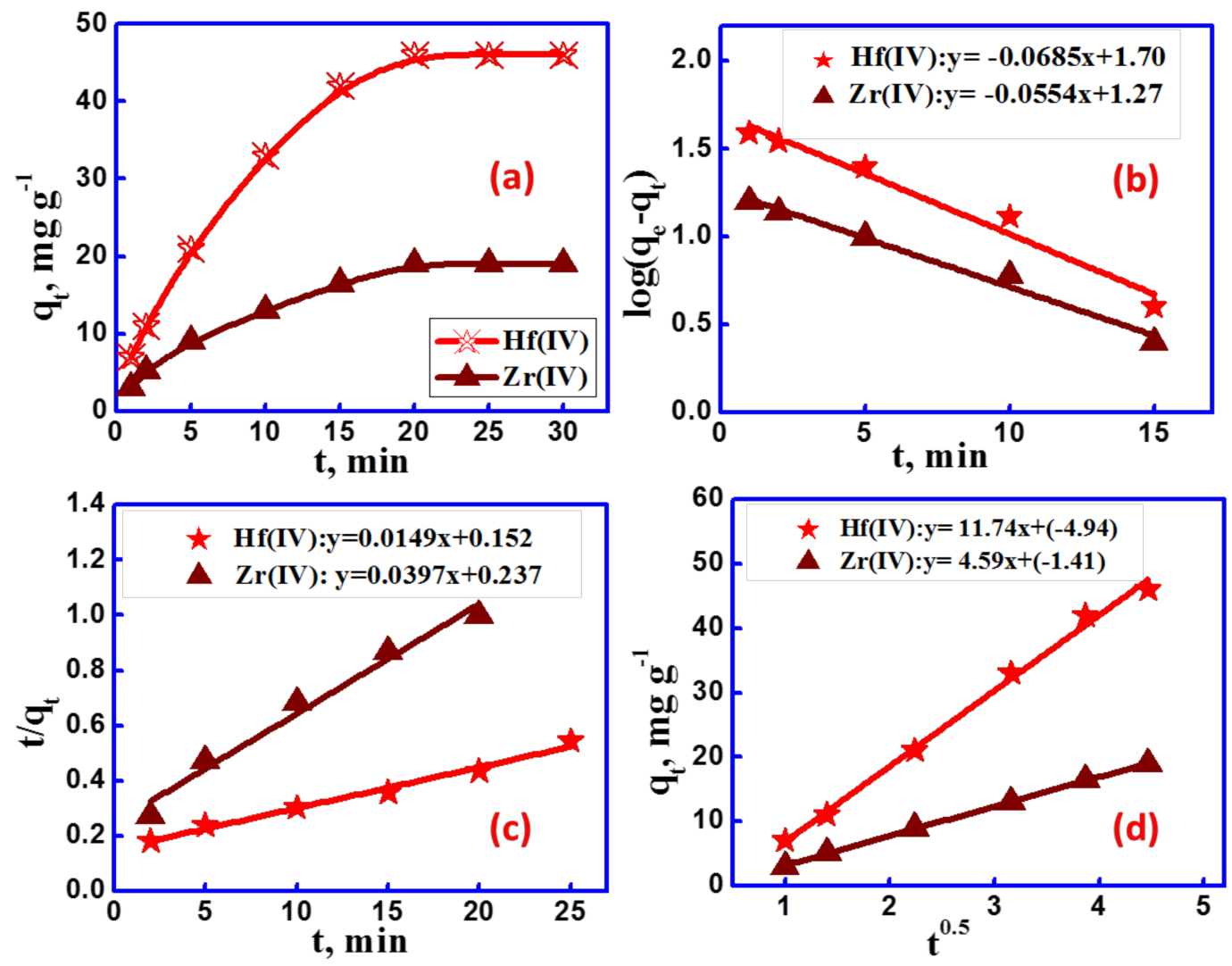

Figure 5. Adsorption of $\mathrm{Zr}(\mathrm{IV})$ and $\mathrm{Hf}(\mathrm{IV})$ on HB/A@Si-MNS as a function of time (a); Pseudo-first order (b); Pseudo-second order (c) and intraparticle diffusion plots (d). 
Table 2. Kinetic parameters for the adsorption of $\mathrm{Zr}(\mathrm{IV})$ and $\mathrm{Hf}(\mathrm{IV})$ on HBMS.

\begin{tabular}{ccccccccccc}
\hline \multirow{2}{*}{ Metal Ion } & \multirow{2}{*}{$\boldsymbol{q}_{\boldsymbol{e}}{\mathbf{~} \mathbf{m g ~ ~ ^ { - 1 }}}$} & \multicolumn{3}{c}{ 1st Order } & \multicolumn{3}{c}{ 2nd Order } & \multicolumn{3}{c}{ IPD } \\
\cline { 2 - 11 } & $Q_{\max }$ & $\boldsymbol{k}_{\mathbf{1}}$ & $\boldsymbol{R}^{\mathbf{2}}$ & $\boldsymbol{Q}_{\max }$ & $\boldsymbol{k}_{\mathbf{2}}$ & $\boldsymbol{R}^{\mathbf{2}}$ & $\boldsymbol{k}_{\boldsymbol{i p}}$ & $\boldsymbol{I}$ & $\boldsymbol{R}^{\mathbf{2}}$ \\
\hline $\mathrm{Zr}(\mathrm{IV})$ & 19 & 18.56 & 0.16 & 0.972 & 25.19 & 0.001 & 0.988 & 11.74 & -4.95 & 0.996 \\
$\mathrm{Hf}(\mathrm{IV})$ & 46 & 50.37 & 0.13 & 0.986 & 67.11 & 0.006 & 0.989 & 4.95 & -1.41 & 0.999 \\
\hline
\end{tabular}

In order to show the effect of the intraparticle diffusion (IPD) on the rate of the adsorption process, the plots between the amount of $\mathrm{Zr}(\mathrm{IV})$ and $\mathrm{Hf}(\mathrm{IV})$ adsorbed at different time intervals $\left(q_{t}\right)$ and the square root of time $\left(t^{0.5}\right)$ were carried out according to IPD model [22-25].

$$
q_{t}=I+k_{i p} t^{0.5}
$$

where $k_{i p}$ is the intraparticle diffusion rate constant $\left(\mathrm{mmol} \mathrm{g}^{-1} \mathrm{~min}^{-0.5}\right)$ and $I$ is a constant equals intercept and is proportional to the thickness of the boundary layer. A higher value of $I$ reflects the pronounced effect of the external film diffusion. The results gave straight lines for $\mathrm{Zr}(\mathrm{IV})$ and $\mathrm{Hf}(\mathrm{IV})$ ions, indicating that the adsorption process is controlled by IPD (Figure $4 \mathrm{c}$ and Table 2). The negative value of I indicates the limited effect of the boundary layer on the rate of adsorption.

\subsubsection{Adsorption Isotherms and Thermodynamic Studies}

Various adsorption models were applied to the experimental adsorption data to verify the adsorption parameters driving the adsorption reaction. The adsorption of $\mathrm{Zr}(\mathrm{IV})$ and $\mathrm{Hf}(\mathrm{IV})$ by HB/A@Si-MNS as a function of equilibrium metal ions concentration at different temperatures were shown in Figure 6. The obtained adsorption curves indicate that the uptake of $\mathrm{Zr}(\mathrm{IV})$ and $\mathrm{Hf}(\mathrm{IV})$ increased as the initial concentration increases. Also, the uptake was found to increase with increased temperature. The maximum uptake value of $\mathrm{Zr}(\mathrm{IV})$ was increased from 19 to $33 \mathrm{mg} \mathrm{g}^{-1}$ with increasing temperature from $25-40{ }^{\circ} \mathrm{C}$, respectively. The maximum uptake value of $\mathrm{Hf}(\mathrm{IV})$ was increased from 46 to $64 \mathrm{mg} \mathrm{g}^{-1}$ with increasing temperature from $25-40{ }^{\circ} \mathrm{C}$, respectively. The linear form of the Langmuir model is given by Equation (7) [32].

$$
\frac{C_{e}}{q_{e}}=\frac{C_{e}}{Q_{\max }}+\frac{1}{K_{L} Q_{\max }}
$$

The values of the Langmuir parameters, $Q_{\max }$ and $K_{L}$, were calculated from the slopes and intercepts of the straight lines (Figure 6) and were reported in Table 3 . At $25{ }^{\circ} \mathrm{C}$, the values of $K_{L}$ are 0.034 and $0.078 \mathrm{~L} \mathrm{mg}^{-1}$ for $\mathrm{Zr}(\mathrm{IV})$ and $\mathrm{Hf}(\mathrm{IV})$, respectively. The observed difference in $K_{L}$ values may be attributed to the different nature of the interaction of both metal ions toward HB/A@Si-MNS. The lower value of $K_{L}$ for $\mathrm{Zr}$ (IV) refers to the lower binding affinity relative to $\mathrm{Hf}(\mathrm{IV})$. The values of $Q_{\max }$ were 24.75 and $54.05 \mathrm{mg} \mathrm{g}^{-1}$ for $\mathrm{Zr}(\mathrm{IV})$ and $\mathrm{Hf}(\mathrm{IV})$, respectively. These values are in good agreement with those obtained experimentally, indicating the validity of the Langmuir model to describe the uptake Zr(IV) and Hf(IV) by HB/A@Si-MNS.

Langmuir adsorption isotherm can be expressed in terms of a dimensionless constant called the equilibrium parameter $\left(R_{L}\right)[24,25]$ :

$$
R_{L}=\frac{1}{1+K_{L} C_{0}}
$$

On application adsorption data to Equation (8), $R_{L}$ values were found between zero and one. This implies that the adsorption of $\mathrm{Zr}(\mathrm{IV})$ and Hf(IV) on HB/A@Si-MNS are favored under the conditions used in this study. 
Table 3. Fitting the adsorption data of $\mathrm{Zr}(\mathrm{IV})$ and $\mathrm{Hf}(\mathrm{IV})$ by HBMS to the Langmuir and Freundlich isotherms.

\begin{tabular}{ccccccccc}
\hline \multirow{2}{*}{ Metal Ion } & \multirow{2}{*}{$\boldsymbol{q}_{\boldsymbol{e}} \mathbf{m g ~ g}^{-\mathbf{1}}$} & \multicolumn{4}{c}{ Langmuir } & \multicolumn{3}{c}{ Freundlich } \\
\cline { 3 - 9 } & & $\boldsymbol{Q}_{\max }$ & $\boldsymbol{K}_{\boldsymbol{L}}$ & $\boldsymbol{R}^{\mathbf{2}}$ & $\boldsymbol{R}_{\boldsymbol{L}}$ & $\boldsymbol{K}_{\boldsymbol{F}}$ & $\boldsymbol{n}$ & $\boldsymbol{R}^{\mathbf{2}}$ \\
\hline $\mathrm{Zr}(\mathrm{IV})$ & 19 & 24.75 & 0.034 & 0.9911 & 0.196 & 2.89 & 2.39 & 0.9884 \\
$\mathrm{Hf}(\mathrm{IV})$ & 46 & 54.05 & 0.078 & 0.9968 & 0.091 & 9.83 & 2.68 & 0.9716 \\
\hline
\end{tabular}
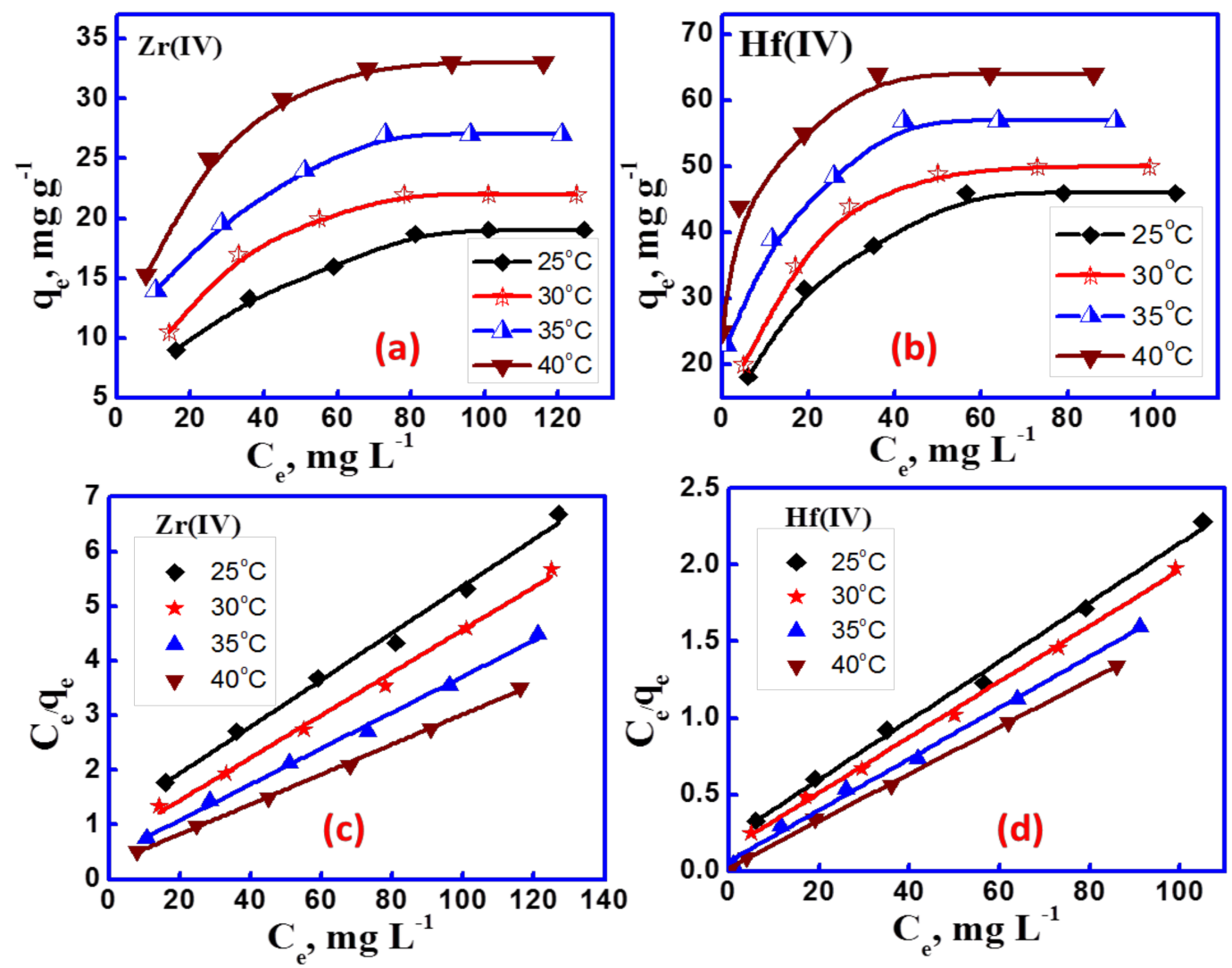

Figure 6. Adsorption isotherms of $\mathrm{Zr}(\mathrm{IV})$ and $\mathrm{Hf}(\mathrm{IV})$ on $\mathrm{HB} / \mathrm{A} @ S i-M N S$ at different temperatures, pH 2.8 and 20 min contact time (a,b). Langmuir plots for the adsorption of $\mathrm{Zr}(\mathrm{IV})$ and $\mathrm{Hf}(\mathrm{IV})$ on HB/A@SI-MNS at different temperatures (c,d).

The Freundlich model is another wide adsorption isotherm that represents the relation between solute concentration and the adsorbent surface affinity. The Freundlich isotherm is defined by (Equation (9)) [31,33].

$$
\log q_{e}=\log K_{F}+\frac{1}{n} \log C_{e}
$$

The plot of $\log q_{e}$ versus $\log C_{e}$ shows that the adsorption of $\mathrm{Zr}(\mathrm{IV})$ and $\mathrm{Hf}(\mathrm{IV})$ on HB/A@Si-MNS do not follow the Freundlich isotherm as shown in Figure 7a. The correlation coefficient values, $R^{2}$, obtained from the Freundlich isotherm were less than those obtained from the Langmuir plots, indicating that the Langmuir model is the more valid isotherm to describe the descriptions of the adsorption process. Thermodynamic parameters were calculated from the linear form of the Van't Hoff equation [34].

$$
\ln K_{L}=\frac{-\Delta H^{\circ}}{R T}+\frac{\Delta S^{\circ}}{R}
$$


where $(R)$ and $T$ are the universal gas constant $\left(8.314 \mathrm{~J} \mathrm{~mol}^{-1} \mathrm{~K}^{-1}\right)$ and absolute temperature $(K)$, respectively. The values of $\Delta H^{\circ}$ and $\Delta S^{\circ}$, Table 4, were calculated from the intercepts and slopes of the straight line plots of $\ln K_{L}$ vs. $1 / T$, Figure $7 \mathrm{~b}$.
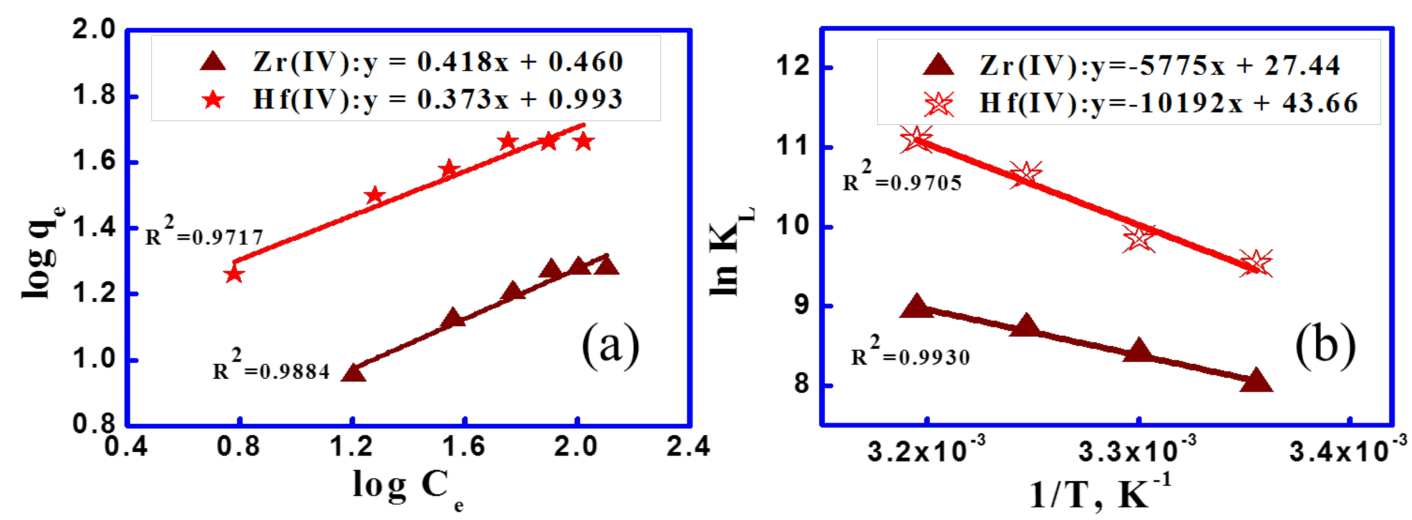

Figure 7. Freundlich plots (a) and Van't Hoff plots for the adsorption of $\mathrm{Zr}(\mathrm{IV})$ and $\mathrm{Hf}(\mathrm{IV})$ on HB/A@Si-MNS (b).

The Gibbs free energy $\left(\Delta G^{\circ}\right)$ for each temperature was calculated using Equation (11).

$$
\Delta G^{\circ}=\Delta H^{\circ}-T \Delta S^{\circ}
$$

The values of $\Delta G^{\circ}$ and $T \Delta S^{\circ}$ were given in Table 4 . The observed increase in the negative values of $\Delta G^{\circ}$ with increasing temperature implies that the adsorption becomes more favorable at a higher temperature. The positive values of $\Delta H^{\circ}$ indicate an endothermic adsorption process. The data given in Table 4 also shows that $\left|\Delta H^{\circ}\right|<\left|-T \Delta S^{\circ}\right|$, this indicates that the adsorption of $\operatorname{Zr}(\mathrm{IV})$ and Hf(IV) on HB/A@Si-MNS are dominated by entropic rather than enthalpic changes.

Table 4. Thermodynamic parameters for adsorption of $\mathrm{Zr}(\mathrm{IV})$ and $\mathrm{Hf}(\mathrm{IV})$ on HBMS at different temperatures.

\begin{tabular}{|c|c|c|c|c|c|c|c|c|}
\hline \multirow[b]{2}{*}{$\mathrm{T},{ }^{\circ} \mathrm{C}$} & \multicolumn{4}{|c|}{$\mathrm{Zr}(\mathrm{IV})$} & \multicolumn{4}{|c|}{ Hf(IV) } \\
\hline & $\begin{array}{c}\Delta H^{\circ}, \\
\mathrm{kJ} / \mathrm{mol}\end{array}$ & $\begin{array}{c}\Delta S^{\circ} \\
\mathrm{kJ} /(\mathrm{mol} \mathrm{K})\end{array}$ & $\begin{array}{c}\Delta G^{\circ} \\
\mathrm{kJ} / \mathrm{mol}\end{array}$ & $\begin{array}{c}T \Delta S^{\circ}, \\
\mathrm{kJ} / \mathrm{mol}\end{array}$ & $\begin{array}{c}\Delta H^{\circ} \\
\mathrm{kJ} / \mathrm{mol}\end{array}$ & $\begin{array}{c}\Delta S^{\circ} \\
\mathrm{kJ} /(\mathrm{mol} \mathrm{K})\end{array}$ & $\begin{array}{c}\Delta G^{\circ} \\
\mathrm{kJ} / \mathrm{mol}\end{array}$ & $\begin{array}{c}T \Delta S^{\circ}, \\
\mathrm{kJ} / \mathrm{mol}\end{array}$ \\
\hline 25 & 84.74 & 0.36 & -23.43 & 108.17 & 48.01 & 0.23 & -19.97 & 67.98 \\
\hline 30 & & & -25.24 & 109.98 & & & -21.11 & 69.12 \\
\hline 35 & & & -27.06 & 111.80 & & & -22.25 & 70.27 \\
\hline 40 & & & -28.87 & 113.61 & & & -23.39 & 71.41 \\
\hline
\end{tabular}

\subsection{Elution and Regeneration}

Sorption/desorption experiments were carried out using the batch method. The metal ions loaded with HB/A@SI-MNS (0.1 g) was washed with distilled water and then subjected to the elution process using $1 \mathrm{M} \mathrm{HNO}_{3}(100 \mathrm{~mL})$ for the different interval time. The concentration of the released metal ions was determined by ICP-MS. After the elution process the HB/A@SI-MNS was washed repeatedly with distilled water (until pH 7), then it was reloaded with metal ions. Both $\mathrm{Zr}(\mathrm{IV})$ and $\mathrm{Hf}(\mathrm{IV})$ were eluted successfully using $1 \mathrm{M} \mathrm{HNO}_{3}$. The elution efficiencies were found to be $94 \%$ and $98 \%$ for $\mathrm{Zr}(\mathrm{IV})$ and Hf(IV), respectively. The regenerated HB/A@SI-MNS showed an uptake capacity comparable to that of fresh ones over three cycles. 


\subsection{Selective Separation of $\mathrm{H} f(I V)$ from $\mathrm{Zr}(I V)$ Metal Ions}

The Selectivity of HB/A@SI-MNS towards Zr(IV) and Hf(IV) was studied from the synthetic mixture as well as from real matrix samples obtained from the Rosetta zircon concentrate. The selective separation experiments were studied using the batch method. The separating factor $(S)$ was calculated using the following equation $[1,2]$.

$$
S_{f}=\frac{\left(q_{e} / C_{e}\right)_{H f}}{\left(q_{e} / C_{e}\right)_{Z r}}
$$

The values of separation factor between $\mathrm{Hf}(\mathrm{IV})$ and $\mathrm{Zr}(\mathrm{IV})$ were found to be (2.7) and (3.5) from Rosetta zircon concentrate and a synthetic mixture, respectively. This indicates that HB/A@SI-MNS has a preferential selectivity towards $\mathrm{Hf}(\mathrm{IV})$ than $\mathrm{Zr}(\mathrm{IV})$ at low $\mathrm{Hf}(\mathrm{IV})$ concentration. Therefore, the studied material may be promising for the effective separation of $\mathrm{Hf}(\mathrm{IV})$ from $\mathrm{Zr}(\mathrm{IV})$.

\section{Conclusions}

In this work, we reported the synthesis of an adsorbent based on the functionalization of mesoporous silica surfaces by HB. HB/A@Si-MNS adsorbent showed an affinity towards $\mathrm{Zr}(\mathrm{IV})$ and $\mathrm{Hf}(\mathrm{IV})$ with maximum uptake values of 33 and $64 \mathrm{mg} \mathrm{g}^{-1}$, respectively. Kinetic and thermodynamic parameters of uptake process were reported and show a pseudo-second-order, spontaneous endothermic adsorption process. The regeneration of the loaded HB/A@Si-MNS was carried out successfully using $1 \mathrm{M} \mathrm{HNO}_{3}$. The separation factor between $\mathrm{Hf}(\mathrm{IV})$ and $\mathrm{Zr}(\mathrm{IV})$ from the Rosetta zircon concentrate and synthetic mixtures showed that HB/A@Si-MNS has a preferential selectivity towards $\mathrm{Hf}(\mathrm{IV})$ than $\mathrm{Zr}(\mathrm{IV})$. The studied adsorbent may be promising for the effective separation of $\mathrm{Hf}(\mathrm{IV})$ from $\mathrm{Zr}(\mathrm{IV})$.

Author Contributions: Mahmoud O. Abd El-Magied and Emad A. Elshehy conceived and designed the experiments; Mahmoud O. Abd El-Magied performed the experiments and analyzed the data; Ahmad A. Daher and Waheed M. Salem contributed reagents/materials/analysis tools; Mahmoud O. Abd El-Magied wrote the paper.

Conflicts of Interest: The authors declare no conflict of interest.

\section{References}

1. Donia, A.M.; Atia, A.A.; Daher, A.M.; Desouky, O.; Elshehy, E.A. Extraction and separation of Zr(IV) from hydrochloric acid solution using modified silica gel produced from waste solution of sodium silicate. Sep. Sci. Technol. 2011, 46, 1329-1336. [CrossRef]

2. Donia, A.M.; Atia, A.A.; Daher, A.M.; Elshehy, E.A. Extraction and separation of zirconium(IV) and hafnium(IV) from chloride media using magnetic resin with phosphoric acid functionality. J. Dispers. Sci. Technol. 2011, 2, 193-202. [CrossRef]

3. Mohammed, N.; Daher, A. Preparation of high-purity zirconia from Egyptian zircon: An anion-exchange purification process. Hydrometallurgy 2002, 65, 103-107. [CrossRef]

4. Daher, A.M.; Abdelkader, A.; El-Kashef, E. Novel decomposition method for zircon. J. Alloys Compd. 2008, 460, 577-580.

5. Barin, I.; Knacke, O.; Kubaschewski, O. Thermochemical Properties of Inorganic Substances; Springer: Berlin, Germany, 1973.

6. Hyde, B.G.; Andersson, S. Inorganic Crystal Structures; John Wiley \& Sons: New York, NY, USA, 1989.

7. El-Barawy, K.A.; El Tawil, S.Z.; Francis, A.A. Alkali fusion of zircon sand. Trans. Inst. Min. Metall. Sect. C 2000, 109, 49-56. [CrossRef]

8. Poriel, L.; Pellet-Rostaing, S.; Lamotte, V.; Lemaire, M.; Favre-Reguillon, A. Zirconium and hafnium separation, part 2. solid/liquid extraction in hydrochloric acid aqueous solution with anion exchange resins. Sep. Sci. Technol. 2006, 41, 2711-2722. [CrossRef]

9. Donia, A.M.; Atia, A.A.; Daher, A.M.; Desouky, O.; Elshehy, E.A. synthesis of amine/thiol magnetic resin and study of its interaction with $\mathrm{Zr}(\mathrm{IV})$ and $\mathrm{Hf}(\mathrm{IV})$ ions in their aqueous solutions. J. Dispers. Sci. Technol. 2011, 32, 634-641. [CrossRef] 
10. Shenashen, M.; Elshehy, E.A.; El-Safty, S.A.; Khairy, M. Visual monitoring and removal of divalent copper, cadmium, and mercury ions from water by using mesoporous cubic Ia3d aluminosilica sensors. Sep. Purif. Technol. 2013, 116, 73-86. [CrossRef]

11. Gao, M.; Ma, Q.; Lin, Q.; Chang, J.; Ma, H. A novel approach to extract $\mathrm{SiO}_{2}$ from fly ash and its considerable adsorption properties. Mater. Des. 2017, 116, 666-675. [CrossRef]

12. Seaton, K.; Little, I.; Tate, C.; Mohseni, R.; Roginskay, M.; Povazhniy, V.; Vasiliev, A. Adsorption of cesium on silica gel containing embedded phosphotungstic acid. Microporous Mesoporous Mater. 2017, 244, 55-66. [CrossRef]

13. Liu, S.; Cui, H.-Z.; Li, Y.-L.; Yang, A.-L.; Zhang, J.-F.; Zhong, R.; Zhou, Q.; Lin, M.; Hou, X.-F. Bis-pyrazolyl functionalized mesoporous SBA-15 for the extraction of $\mathrm{Cr}(\mathrm{III})$ and detection of $\mathrm{Cr}(\mathrm{VI})$ in artificial jewelry samples. Microchem. J. 2017, 131, 130-136. [CrossRef]

14. El-Safty, S.A.; Shenashen, M.A.; Sakai, M.; Elshehy, E.; Halada, K. Detection and recovery of palladium, gold and cobalt metals from the urban mine using novel sensors/adsorbents designated with nanoscale wagon-wheel-shaped pores. J. Vis. Exp. 2015, 106, 53044. [CrossRef] [PubMed]

15. Lewandowski, D.; Cegłowski, M.; Smoluch, M.; Reszke, E.; Silberring, J.; Schroeder, G. Magnetic mesoporous silica $\mathrm{Fe}_{3} \mathrm{O}_{4} @ \mathrm{SiO}_{2} @$ meso- $\mathrm{SiO}_{2}$ and $\mathrm{Fe}_{3} \mathrm{O}_{4} @ \mathrm{SiO}_{2} @$ meso- $\mathrm{SiO}_{2}-\mathrm{NH}_{2}$ as adsorbents for the determination of trace organic compounds. Microporous Mesoporous Mater. 2017, 240, 80-90. [CrossRef]

16. Ghosh, S.; Vandana, V. Nano-structured mesoporous silica/silver composite: Synthesis, characterization and targeted application towards water purification. Mater. Res. Bull. 2017, 88, 291-300. [CrossRef]

17. Qin, W.; Xu, S.; Xu, G.; Xie, Q.; Wang, C.; Xu, Z. Preparation of silica gel bound crown ether and its extraction performance towards zirconium and hafnium. Chem. Eng. J. 2013, 225, 528-534. [CrossRef]

18. Guo, X.; Feng, Y.; Ma, L.; Gao, D.; Jing, J.; Yu, J.; Sun, H.; Gong, H.; Zhang, Y. Phosphoryl functionalized mesoporous silica for uranium adsorption. App. Surf. Sci. 2017, 402, 53-60.

19. Guo, X.; Feng, Y.; Ma, L.; Gao, D.; Jing, J.; Yu, J.; Sun, H.; Gong, H.; Zhang, Y. Adsorbents based on crown ether functionalized composite mesoporous silica for selective extraction of trace silver. Chem. Eng. J. 2017, 313, 1278-1287.

20. Zhou, Y.; Li, X.; Chen, Z. Rapid synthesis of well-ordered mesoporous silica from sodium silicate. Powder Technol. 2012, 226, 239-245. [CrossRef]

21. Marczenko, Z. Separation and Spectrophotometric Determination of Elements; Ellis Harwood: Chichester, UK, 1986.

22. Abd El-Magied, M.O.; Galhoum, A.A.; Atia, A.A.; Tolba, A.A.; Maize, M.S.; Vincent, T.; Guibal, E. Cellulose and chitosan derivatives for enhanced sorption of erbium(III). Colloids Surf. A Physicochem. Eng. Asp. 2017, 529, 580-593. [CrossRef]

23. Böhmer, V.; Dozol, J.F.; Grüttner, C.; Liger, K.; Matthews, S.E.; Rudershausen, S.; Saadioui, M.; Wang, P.; Org, P. Separation of lanthanides and actinides using magnetic silica particles bearing covalently attached tetra-CMPO-calix[4]arenes. Org. Biomol. Chem. 2004, 2, 2327-2334. [CrossRef] [PubMed]

24. Elshehy, E.A.; Shenashen, M.A.; Abd El-Magied, M.O.; El-Nahas, A.M.; Tolan, D.A.; Halada, K.; Atia, A.A.; El-Safty, S.A. Selective recovery of silver (I) ions from e-waste using cubically multi-thiolated cage mesoporous monoliths. Eur. J. Inorg. Chem. 2017, 2017, 4823-4833. [CrossRef]

25. Abd El-Magied, M.O.; Elshehy, E.A.; Manaa, E.; Tolba, A.; Atia, A.A. Kinetics and thermodynamics studies on the recovery of thorium ions using amino resins with magnetic properties. Ind. Eng. Chem. Res. 2016, 55, 11338-11345. [CrossRef]

26. Poriel, L.; Favre-Réguillon, A.; Pellet-Rostaing, S.; Lemaire, M. Zirconium and hafnium separation, part 1. liquid/liquid extraction in hydrochloric acid aqueous solution with aliquat 336. Sep. Sci. Technol. 2006, 41, 1927-1940. [CrossRef]

27. Abdel-Fattah, A.A.; Ali, S.M.; El-Sweify, F.H. Thermodynamics of the solvent extraction of $\operatorname{Zr}(\mathrm{IV})$ by Amberlite LA-2, TBP and HDEHP from different aqueous media. J. Radioanal. Nucl. Chem. 2002, 253, 465-475. [CrossRef]

28. Lee, M.S.; Lee, H.Y. Distribution of $\mathrm{Zr}(\mathrm{IV})$ ion species in aqueous solution. J. Korean Inst. Resour. Recycl. 2011, 20, 56-62. [CrossRef]

29. Wang, L.Y.; Lee, M.S. A review on the aqueous chemistry of $\mathrm{Zr}(\mathrm{IV})$ and $\mathrm{Hf}(\mathrm{IV})$ and their separation by solvent extraction. J. Ind. Eng. Chem. 2016, 39, 1-9. [CrossRef]

30. Sadeek, S.A.; El-Sayed, M.A.; Amine, M.M.; Abd El-Magied, M.O. Selective solid-phase extraction of U(VI) by amine functionalized glycidyl methacrylate. J. Environ. Chem. Eng. 2014, 2, 293-303. [CrossRef] 
31. Sadeek, S.A.; Moussa, E.M.M.; El-Sayed, M.A.; Amine, M.M.; Abd El-Magied, M.O. Uranium(VI) and Thorium(IV) adsorption studies on chelating resin containing pentaethylenehexamine as a functional group. J. Dispers. Sci. Technol. 2014, 35, 926-933. [CrossRef]

32. Langmuir, I. The adsorption of gases on plane surfaces of glass, mica and platinum. J. Am. Chem. Soc. 1918, 40, 1361-1403. [CrossRef]

33. Freundlich, H.M.F. Over the adsorption in solution. J. Phys. Chem. 1906, 57, 385-470.

34. Abd El-Magied, M.O.; Tolba, A.; El-Gendy, H.; Zaki, S.; Atia, A.A. Studies on the recovery of Th(IV) ions from nitric acid solutions using amino-magnetic glycidyl methacrylate resins and application to granite leach liquors. Hydrometallurgy 2017, 169, 89-98. [CrossRef]

(C) 2018 by the authors. Licensee MDPI, Basel, Switzerland. This article is an open access article distributed under the terms and conditions of the Creative Commons Attribution (CC BY) license (http://creativecommons.org/licenses/by/4.0/). 